\title{
Erratum to: Characterization of the dengue outbreak in Nuevo Leon state, Mexico, 2010
}

\author{
D. Leduc-Galindo $\cdot$ U. Gloria-Herrera $\cdot$ J. Ramos-Jiménez $\cdot$ S. Garcia-Luna $\cdot$ D. Arellanos-Soto $\cdot$ \\ N. Mendoza-Tavera $\cdot$ I. Tavitas-Aguilar $\cdot$ E. Garcia-Garcia $\cdot$ E. Galindo-Galindo $\cdot$ J. Villarreal-Perez $\cdot$ \\ I. Fernandez-Salas · G. A. Santiago · J. Muñoz-Jordan · A. M. Rivas-Estilla
}

Published online: 21 February 2015

(C) Springer-Verlag Berlin Heidelberg 2015

\section{Erratum to: Infection}

DOI 10.1007/s15010-014-0700-7

Unfortunately, one of the co-author names has been misspelled in the published article. The second author name should be changed, instead of U. Rincon-Herrera should be U. Gloria-Herrera.
The online version of the original article can be found under doi:10.1007/s15010-014-0700-7.

\section{Leduc-Galindo · U. Gloria-Herrera $\cdot$ S. Garcia-Luna}

D. Arellanos-Soto · A. M. Rivas-Estilla $(\triangle)$

Department of Biochemistry and Molecular Medicine, Facultad de Medicina and Hospital Universitario "Dr. José E. Gonzalez", Universidad Autónoma de Nuevo León, Av. Francisco I. Madero y Eduardo Aguirre Pequeño s/n Col. Mitras Centro, CP 64460 Monterrey, Nuevo León, Mexico

e-mail: amrivas1@yahoo.ca

J. Ramos-Jiménez $\cdot$ N. Mendoza-Tavera $\cdot$ J. Villarreal-Perez Department of Internal Medicine, Facultad de Medicina and Hospital Universitario "Dr. José E. Gonzalez", Universidad Autónoma de Nuevo León, Monterrey, Nuevo León, Mexico

I. Tavitas-Aguilar · E. Garcia-Garcia · E. Galindo-Galindo · J. Villarreal-Perez

Nuevo León Reference Laboratory of Secretariat of Health, Monterrey, Nuevo León, Mexico

\author{
I. Fernandez-Salas \\ Department of Entomology, School of Biological Sciences, \\ Universidad Autónoma de Nuevo León, San Nicolás de los \\ Garza, Monterrey, Nuevo León, Mexico \\ G. A. Santiago $\cdot$ J. Muñoz-Jordan \\ Division of Vector-Borne Infectious Diseases, National Center \\ for Zoonotic, Vector-Borne, and Enteric Diseases, Centers \\ for Disease Control and Prevention, San Juan, PR, USA
}

